Editorial

\title{
Special Issue Editorial: Earth Observation and Geoinformation Technologies for Sustainable Development
}

\author{
Jamal Jokar Arsanjani ${ }^{1, *}$ and Eric Vaz ${ }^{2}$ \\ 1 Geoinformatics Research Group, Department of Planning, Aalborg University Copenhagen, \\ A.C. Meyers Vænge 15, DK-2450 Copenhagen, Denmark \\ 2 Department of Geography and Environmental Studies, Ryerson University, Toronto, ON M5B 2K3, Canada; \\ evaz@ryerson.ca \\ * Correspondence: jja@plan.aau.dk
}

Academic Editor: Marc Rosen

Received: 2 April 2017; Accepted: 25 April 2017; Published: 5 May 2017

This editorial presents an introduction to fourteen papers published in the Special Issue of Earth Observation and Geoinformation Technologies for Sustainable Development in the Sustainability journal.

Geoinformation has become increasingly important in understanding the impacts of earth observation on urban regions, the natural environment, and landscape transitions. With the advance of Geocomputational technologies, the epistemological understanding of Geographic Information Science has become a ubiquitous field to advance new tools for sustainable development and regional decision support systems [1]. Additionally, emerging active and passive sensing approaches, such as crowdsourcing, Volunteered Geographic Information [2], citizen science, participatory sensing, humans-as-sensors, as well as new techniques in fine-scale mapping [3] have allowed to leverage the prior way of monitoring and sensing our landscapes [4]. One of the main advantages corresponds to the integration of different multidisciplinary approaches for implementation in the real world situation by practitioners, scholars, and planners alike. This results in a core of better environmental management and planning strategies, nurtured by a multidisciplinary vision that stems from the nested complexity of sustainable development. In this sense, Geoformation has promptly offered leading tools for sustainable development and spatial decision support systems.

The extensive demographic shifts, through population dynamics, where human activity and impacts on the fringes of urban environments, need urgent monitoring to cope with the ongoing population growth [5]. Moreover, humans have been consuming more resources than ever. Thus, spatial and temporal monitoring efforts should be carried forth, so as to achieve a better understanding of our environment and its inhabitants, and to allow for a coherent approach to sustainable development. Multidisciplinary approaches can benefit from becoming leveraged by geoinformation technologies; these approaches should be undertaken for a better and deeper understanding of human-environment interactions.

Earth observation devices and geoinformation technologies, including remote sensing data, platforms, algorithms, geographic information science, and spatial analysis techniques have played a major role in monitoring the dynamics of our environment and landscape. Additionally, emerging active and passive sensing approaches, such as crowdsourcing, Volunteered Geographic Information, citizen science, participatory sensing, humans-as-sensors, etc., have allowed us to leverage the prior way of monitoring and sensing our landscapes. Both approaches provide a great deal of data and methodologies to scientists, practitioners, and planners, thus enabling a more efficient planning and design of the environment. This results in better environmental management and sustainable development and must be considered for better decision making. 
In addition to the unprecedented growth of the world population, human activity has become more diversified than ever. Moreover, humans have been consuming more resources than ever. Thus, spatial and temporal monitoring efforts should be carried forth, so as to achieve a better understanding of our environment and its inhabitants, and to allow for a coherent approach to sustainable development. Multidisciplinary approaches can benefit from becoming leveraged by geoinformation technologies; these approaches should be undertaken for a better and deeper understanding of human-environment interactions.

To address these issues, the prime aim of this Special Issue is to provide a set of innovative and pioneering contributions to the traditional approaches in regard to the aforementioned issues. Furthermore, it focuses on the emerging opportunities and challenges of geoinformation, as innovative spatial analysis techniques and land policy and management issues progress via technological and computational advances. This collection of papers provides a selection of interesting approaches and methodologies useful for, but not limited to, audiences that include researchers, practitioners, and professionals.

We started by announcing widely the call for papers for this Special Issue, and invited leading scholars to contribute. It received a great response from a significant number of scholars. By the deadline for submission in May 2016, a total number of 41 submissions were submitted. Through a single-blind review process following standard MDPI review guidelines, we invited at least two expert reviewers to review the manuscripts and comment on the quality, originality, relevance, as well as fit for the Special Issue. This led to 14 accepted manuscripts out of the 41 submitted (almost $34 \%$ acceptance rate) for publication and these were thus included in the Special Issue.

The Special Issue consists of the following papers: Naranjo Gómez [6] studies the impacts of Mainland Spain's Future Motorway and High-Speed Rail Networks on Social Cohesion by classifying Spanish municipalities according to the degree of socioeconomic development as well as their accessibility levels prior and post construction of these infrastructures. As a result, social cohesion across different municipalities was mapped and the interaction between them investigated. Gao et al. [7] develop a new interpretation system to grade and classify saline-alkali lands in Huanghua City of China across space and time based on the characteristics of plant cover and remote sensing images. Their results reveal dynamic spatiotemporal changes of cultivated lands under saline-alkali conditions in the study area. Miao et al. [8] measure the species composition and density of the soil seed bank, as well as the species composition, density, coverage, and height of the extant vegetation in sites passively restored for $0,4,7$, and 12 years in order to evaluate the efficacy of passive restoration on soil seed bank and vegetation recovery. They conclude that passive restoration is a useful method to recover the soil seed bank and vegetation in degraded grasslands.

Kablak [9] investigate the spatiotemporal instability in the atmosphere, based on 845 temporal measurements of tropospheric delay over the territory covered by 20 active reference stations of the UA-EUPOS/ZAKPOS network. Their proposed method can be used to improve the quality of weather forecasts and the prevention of natural disasters. Nunes et al. [10] collect the geological characterization of the Caia Irrigation Perimeter in Portugal and information about the topography, climate, and vegetation of the region using the Food and Agriculture Organization of the United Nations (FAO) methodology and generate a large-scale soil map adequate for the demands of modern and intensive agriculture. The resultant map is characterized by enormous heterogeneity, typical of Mediterranean soils, containing 23 distinct cartographic units, the most representative being the Distric Fluvisols with inclusions of Luvisols Distric, Calcisols Luvic, and Luvisols endoleptic. Wang et al. [11] integrate the assessment of hillslope and gully erosion in order to explore spatial coupling relations between them in the Mushi River sub-catchment in China using geographical conditions monitoring (GCM) including remote sensing and geographic information science based on the revised universal soil loss equation (RUSLE) model. Their findings promote a better understanding of the spatial coupling relationships between hillslope and gully erosion. 
Huang and $\mathrm{Xu}$ [12] use time series SPOT VEGETATION (SPOT-VGT) Normalized Difference Vegetation Index (NDVI) images and precipitation data for Songliao Plain from 1999 to 2011 to calculate satellite-based rain-use efficiency (RUE). Their results demonstrate that vegetation RUE increased slightly with an undulating trend, implying that the ecosystem function tended to improve between 1999 and 2011. Johansson et al. [13], using Gällivare, Sweden data, present a method that highlights social values in spatial models through $3 \mathrm{D}$ visualization and explain the methodology to generate the models, and finally discuss its potential applications. Their models help to identify spatial variations in perceptions of the built environment that correlate with closeness to certain locations, gender and distances to public buildings. Finally, they discuss the potential uses of their model for supporting efforts by practitioners, researchers and citizens to visualize and understand social values in similar urban environments together with ethical issues concerning its wider use for inclusive planning.

Wang et al. [14] propose a model for landslide susceptibility zonation mapping and its susceptibility based on modifying the Information Value Model to make the Modified Information Value (MIV) Model. They provide a discussion about the usefulness and performance measure of their model. Kil et al. [15] employ a diverse set of variables to explain slope stabilization on stable versus failure-prone revegetated cut-slopes in Korea. Through a non-parametric test of the field survey results, 15 variables are identified as primary determinants of slope failure. Among them, one describes physical characteristics, i.e., elapsed year; four variables describe vegetation properties including plant community, vegetation coverage rate, number of trees, and number of herbs; and 10 variables represent soil properties such as porosity, soil hardness, water content, sand to silt ratio of soil texture, tensile strength, permeability coefficient, soil depth, soil acidity, salt concentration, and organic matter.

Feng et al. [16] utilize multi-temporal Landsat imagery to study the cropland dynamics of the Yellow River Delta during the last three decades. A robust random forest classifier was used to generate the land cover maps of the Yellow River Delta within the period 1986-2015 with an average classification accuracy of $89.44 \%$. A spatio-temporal analysis indicates an increase of the croplands with an average growth rate of $8.65 \mathrm{~km}^{2} /$ year. They conclude that a sustainable perspective should be adopted by the decision makers in order to simultaneously maintain food security, industrial development and ecosystem safety. Zhang et al. [17] undertake a study to develop an appropriate plan of land use under a suitable slope gradient to control soil erosion from a watershed of southern China by using the GeoWEPP (Geo-spatial Interface for the Water Erosion Prediction Project) model within the period 2010-2012. Subsequently, their model is used to simulate four typical land uses (forest, farm, orchard, and fallow land) in the study area to evaluate their impacts on soil erosion production. Their conclusions provide decent scientific evidence for developing an appropriate land use plan in the study area based on their results.

Xu et al. [18] conduct a study using the Night Light Development Index (NLDI) to measure the regional inequality of public services in Mainland China at multiple scales. The NLDI was extracted based on a Gini Coefficient approach to measure the spatial differences of population distribution and night light distribution. The results indicate that Southwest China and Northwest China are the regions with the most unequal public services. In contrast, Northern Coastal China had the lowest NLDI values, indicating that this region had the most equal public services. Their results indicate that provincial and prefectural regions with more public services per capita and higher population density had more equal public services. Chen et al. [19] conduct a study for Laoshan forest in Nanjing based on Landsat-5 TM data to determine whether the temperature vegetation dryness index (TVDI) is suitable to estimate the soil moisture and if soil moisture is significantly affected by tree species. Their analysis shows that there is a strong negative correlation between the TVDI and the in situ measured soil moisture, which underlines that the TVDI can reflect the soil moisture status under different tree species.

In conclusion, these papers demonstrate a great deal of contribution from remote sensing data combined with in situ observations embedded in a geographic information system in order to study our surrounding environments with the aim of increasing sustainability across different 
continents. There was, however, no submission dealing with crowdsourced data and volunteered geographic information in studying our landscapes and their integration with remote sensing and in situ observations. The papers suggest a plethora of available tools that combine the evidence of advances in geoinformation technologies geared towards sustainability. The selection addresses a broad range of different issues, leveraging on the multidisciplinary vision of Geographic Information Science and the ubiquitous nature of geoinformation technologies. It is our opinion that the wealth of diversified tools available within the field of geoinformation technologies will steer this area to become an increasingly present concept in planning and decision making. The fundamental need to address change and sustainability juxtaposed by the complexity of the challenges presently faced may well incorporate systematic visions of geoinformation to complement a better and more sustainable future.

Acknowledgments: The editors express their gratefulness and gratitude to all reviewers for their support and their critical and constructive comments for these manuscripts. This has improved significantly the quality of this collection. Finally, we would like to thank the editorial assistance office of MDPI for their support throughout the review and publication process of this Special Issue.

Author Contributions: Jamal Jokar Arsanjani and Eric Vaz wrote the paper. Jamal Jokar Arsanjani managed the editorial process and publication.

Conflicts of Interest: The authors declare no conflict of interest.

\section{References}

1. Vaz, E. The future of landscapes and habitats: The regional science contribution to the understanding of geographical space. Habitat Int. 2016, 51, 70-78. [CrossRef]

2. Vaz, E.; Arsanjani, J.J. Crowd sourced mapping of land use in urban dense environments: An assessment of Toronto. Can. Geogr. 2015, 59, 246-255. [CrossRef]

3. Arsanjani, J.J.; Tayyebi, A.; Vaz, E. GlobeLand30 as an alternative fine-scale global land cover map: Challenges, possibilities, and implications for developing countries. Habitat Int. 2016, 55, 25-31. [CrossRef]

4. Arsanjani, J.J.; Vaz, E. An assessment of a collaborative mapping approach for exploring land use patterns for several European metropolises. Int. J. Appl. Earth Obs. Geoinf. 2015, 35, 329-337. [CrossRef]

5. Vaz, E.; Lee, K.; Moonilal, V.; Pereira, K. Potential of Geographic Information Systems for Refugee Crisis: Syrian Refugee Relocation in Urban Habitats. Habitat Int. 2017. [CrossRef]

6. Naranjo Gómez, J.M. Impacts on the Social Cohesion of Mainland Spain's Future Motorway and High-Speed Rail Networks. Sustainability 2016, 8, 624. [CrossRef]

7. Gao, H.; Liu, J.; Eneji, A.E.; Han, L.; Tan, L. Using Modified Remote Sensing Imagery to Interpret Changes in Cultivated Land under Saline-Alkali Conditions. Sustainability 2016, 8, 619. [CrossRef]

8. Miao, R.; Song, Y.; Sun, Z.; Guo, M.; Zhou, Z.; Liu, Y. Soil Seed Bank and Plant Community Development in Passive Restoration of Degraded Sandy Grasslands. Sustainability 2016, 8, 581. [CrossRef]

9. Kablak, N.; Reity, O.; Ştefan, O.; Rădulescu, A.T.G.M.; Rădulescu, C. The Remote Monitoring of Earth's Atmosphere Based on Operative Processing GNSS Data in the UA-EUPOS/ZAKPOS Network of Active Reference Stations. Sustainability 2016, 8, 391. [CrossRef]

10. Nunes, J.R.; Loures, L.; Lopez-Piñeiro, A.; Loures, A.; Vaz, E. Using GIS towards the Characterization and Soil Mapping of the Caia Irrigation Perimeter. Sustainability 2016, 8, 368. [CrossRef]

11. Wang, R.; Zhang, S.; Yang, J.; Pu, L.; Yang, C.; Yu, L.; Chang, L.; Bu, K. Integrated Use of GCM, RS, and GIS for the Assessment of Hillslope and Gully Erosion in the Mushi River Sub-Catchment, Northeast China. Sustainability 2016, 8, 317. [CrossRef]

12. Huang, F.; Xu, S. Spatio-Temporal Variations of Rain-Use Efficiency in the West of Songliao Plain, China. Sustainability 2016, 8, 308. [CrossRef]

13. Johansson, T.; Segerstedt, E.; Olofsson, T.; Jakobsson, M. Revealing Social Values by 3D City Visualization in City Transformations. Sustainability 2016, 8, 195. [CrossRef]

14. Wang, Q.; Wang, D.; Huang, Y.; Wang, Z.; Zhang, L.; Guo, Q.; Chen, W.; Chen, W.; Sang, M. Landslide Susceptibility Mapping Based on Selected Optimal Combination of Landslide Predisposing Factors in a Large Catchment. Sustainability 2015, 7, 16653-16669. [CrossRef] 
15. Kil, S.-H.; Lee, D.K.; Kim, H.G.; Kim, N.-C.; Im, S.; Park, G.-S. Comparing Potential Unstable Sites and Stable Sites on Revegetated Cut-Slopes of Mountainous Terrain in Korea. Sustainability 2015, 7, 15319-15341. [CrossRef]

16. Feng, Q.; Gong, J.; Liu, J.; Li, Y. Monitoring Cropland Dynamics of the Yellow River Delta based on Multi-Temporal Landsat Imagery over 1986 to 2015. Sustainability 2015, 7, 14834-14858. [CrossRef]

17. Zhang, Z.; Sheng, L.; Yang, J.; Chen, X.; Kong, L.; Wagan, B. Effects of Land Use and Slope Gradient on Soil Erosion in a Red Soil Hilly Watershed of Southern China. Sustainability 2015, 7, 14309-14325. [CrossRef]

18. Xu, H.; Yang, H.; Li, X.; Jin, H.; Li, D. Multi-Scale Measurement of Regional Inequality in Mainland China during 2005-2010 Using DMSP/OLS Night Light Imagery and Population Density Grid Data. Sustainability 2015, 7, 13469-13499. [CrossRef]

19. Chen, S.; Wen, Z.; Jiang, H.; Zhao, Q.; Zhang, X.; Chen, Y. Temperature Vegetation Dryness Index Estimation of Soil Moisture under Different Tree Species. Sustainability 2015, 7, 11401-11417. [CrossRef]

(C) 2017 by the authors. Licensee MDPI, Basel, Switzerland. This article is an open access article distributed under the terms and conditions of the Creative Commons Attribution (CC BY) license (http://creativecommons.org/licenses/by/4.0/). 